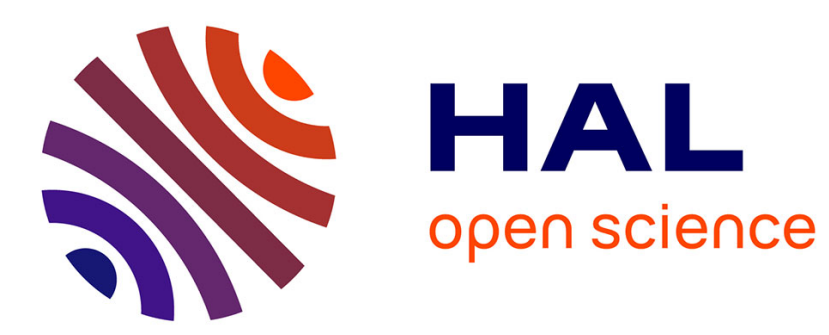

\title{
Water dimer absorption of visible light
}

\author{
J. Hargrove
}

\section{To cite this version:}

J. Hargrove. Water dimer absorption of visible light. Atmospheric Chemistry and Physics Discussions, 2007, 7 (4), pp.11123-11140. hal-00303013

\section{HAL Id: hal-00303013 \\ https://hal.science/hal-00303013}

Submitted on 27 Jul 2007

HAL is a multi-disciplinary open access archive for the deposit and dissemination of scientific research documents, whether they are published or not. The documents may come from teaching and research institutions in France or abroad, or from public or private research centers.
L'archive ouverte pluridisciplinaire HAL, est destinée au dépôt et à la diffusion de documents scientifiques de niveau recherche, publiés ou non, émanant des établissements d'enseignement et de recherche français ou étrangers, des laboratoires publics ou privés. 
Atmos. Chem. Phys. Discuss., 7, 11123-11140, 2007

www.atmos-chem-phys-discuss.net/7/11123/2007/

(C) Author(s) 2007. This work is licensed

under a Creative Commons License.

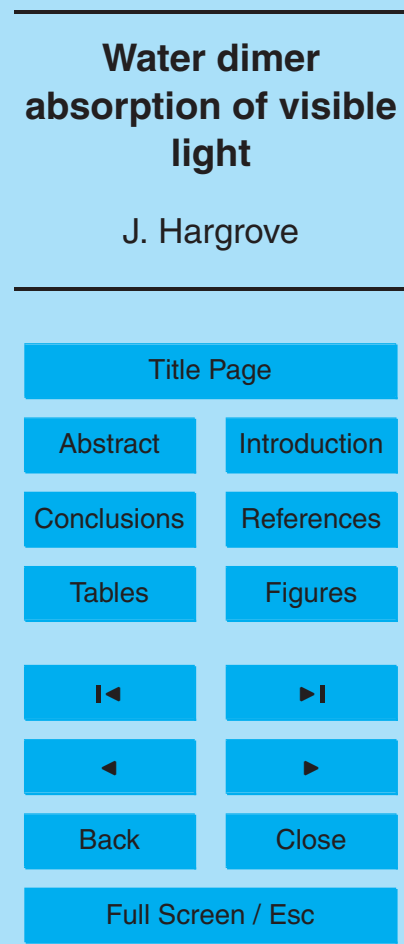

\section{Water dimer absorption of visible light}

\section{J. Hargrove}

Department of Chemistry, University of California, Riverside, CA 92521, USA

Received: 4 July 2007 - Accepted: 19 July 2007 - Published: 27 July 2007

Correspondence to: J. Hargrove (hjamestwo@yahoo.com) 


\section{Abstract}

Laboratory measurements of water vapor absorption using cavity ring-down spectroscopy revealed a broad absorption at $405 \mathrm{~nm}$ with a quadratic dependence on water monomer concentration, a similar absorption with a linear component at $532 \mathrm{~nm}$, and 5 only linear absorption at $570 \mathrm{~nm}$ in the vicinity of water monomer peaks. $\mathrm{D}_{2} \mathrm{O}$ absorption is weaker and linear at $405 \mathrm{~nm}$. Van't Hoff plots constructed at $405.26 \mathrm{~nm}$ suggest that for dimerization, $\mathrm{K}_{\mathrm{eq}}=0.056 \pm 0.02 \mathrm{~atm}^{-1}, \Delta \mathrm{H}_{301 \mathrm{~K}}^{\circ}=-16.6 \pm 2 \mathrm{~kJ} \mathrm{~mol}^{-1}$ and $\Delta \mathrm{S}_{301 \mathrm{~K}}^{\circ}=-80 \pm 10 \mathrm{~J} \mathrm{~mol}^{-1} \mathrm{~K}^{-1}$. This transition peaks at $409.5 \mathrm{~nm}$, could be attributed to the 8th overtone of water dimer and the $532 \mathrm{~nm}$ absorption to the 6th overtone. It is 10 possible that some lower overtones previously searched for are less enhanced. These absorptions could increase water vapor feed back calculations leading to higher global temperature projections with currently projected greenhouse gas levels or greater cooling from greenhouse gas reductions.

\section{Introduction}

15 The balance of energy between incoming radiation to the earth and blackbody radiation emitted by the earth and absorbed by the atmosphere critically affects global temperatures and is calculated by models of radiative forcing. Water vapor feedback has a positive effect on global temperatures (Held and Soden, 2000), but the magnitude of this effect is 2 to 3 times stronger than models predict (Fomin and Udalova, 2003; Philipona, 2005; Durr et al., 2005). One component of water vapor feedback is direct absorption. An, as yet unidentified, absorption in the short wavelength region has been predicted by Arking from modeling and long path-length measurements in the atmosphere. The resulting estimation of $15-30 \mathrm{~W} \mathrm{~m}^{-2}$ could cause a difference of $4^{\circ} \mathrm{C}$ in the calculated average surface temperature of the earth (Carlon, 1979; Arking, 25 1996, 1999). Observations of this anomalous absorption found that the discrepancy was measurable in tropical regions and near clouds (Hill and Jones, 2000), but were

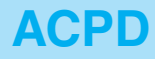

7, 11123-11140, 2007

\section{Water dimer \\ absorption of visible light \\ J. Hargrove}

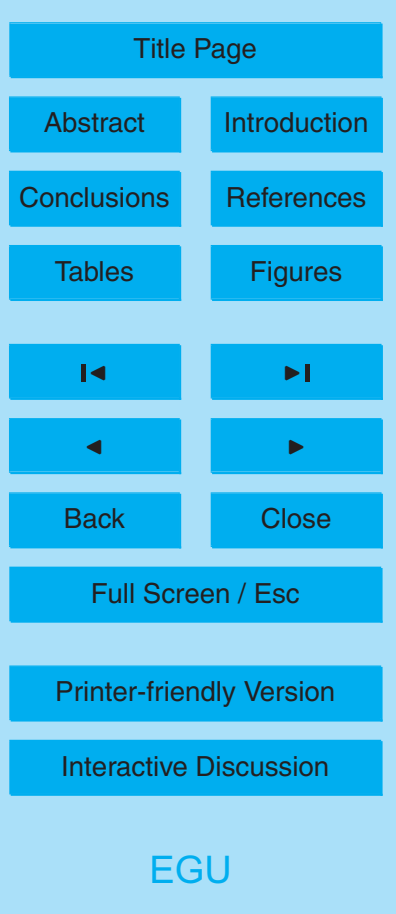


complicated by the presence of scattering by particulates. Potential sources of the additional absorption include absorptions due to water dimer and water far wing continuum absorption. Water dimer has been calculated to absorb $3-6 \mathrm{~W} \mathrm{~m}^{-1}$ of solar radiation from calculations that used an outdated model for Helium clusters (Tso et al., 5 1998), and were then recalculated to be less (Vaida, 2001; Daniel et al. 2001). A third paper suggested that vibrational levels above the dissociation limit make the absorptions even stronger (Schenter, 2002; Kathmann et al., 2002). The results of this study suggest the absorption might actually be higher, but it is not clear whether levels above the dissociation limit are enough to explain the magnitude of the measurements by our 10 laboratory (Hargrove, 2006; Wang et al., 2006), and an additional theoretical mechanism might need to be invoked to explain these results. This paper further explores this water absorption and establishes some evidence that it is due to water dimer.

Water vapor continuum absorption has been measured previously, but only in the microwave, infrared and near infrared regions of the spectrum (English, 1994; Guillou 15 et al., 1994; Hewison 2006). In the near infrared, Sierk et al. reported water dimer absorption between 880 and $1000 \mathrm{~nm}$ using differential optical absorption spectroscopy (DOAS) (Sierk, 2004; Solomon et al., 2004), since then Cormier et al. have done a meticulous study of water vapor continuum absorption at $944 \mathrm{~nm}$ determining additionally the effect of water nitrogen complexes and water oxygen complexes using cavity 20 ring-down spectroscopy (CRDS) (Cormier, 2005; Hodges et al., 2005). Notably, in 2003 a water vapor band was mistakenly attributed to water dimer (Pfeilsticker, 2004; Lotter et al., 2003), but was shown to be too narrow to be water dimer (Pfeilsticker, 2004). It may be that attempts to observe lower overtones of water dimer have been unsuccessful due to a cancellation effect of the water dipoles that was noticed in intramolecular 25 hydrogen bonded species (Howard and Kjaergaard, 2006). At $750 \mathrm{~nm}$ the water vapor continuum was determined to be not detectable by CRDS (Kassi, 2005; Macko et al., 2005) Carleer et al. (2003) measured a broad feature in the visible spectrum of water and attributed it to possible scattering by $1 \mu \mathrm{m}$ water droplets and noted correctly that this is unlikely because their measurements were taken at water concentration levels

\section{Water dimer absorption of visible light \\ J. Hargrove}

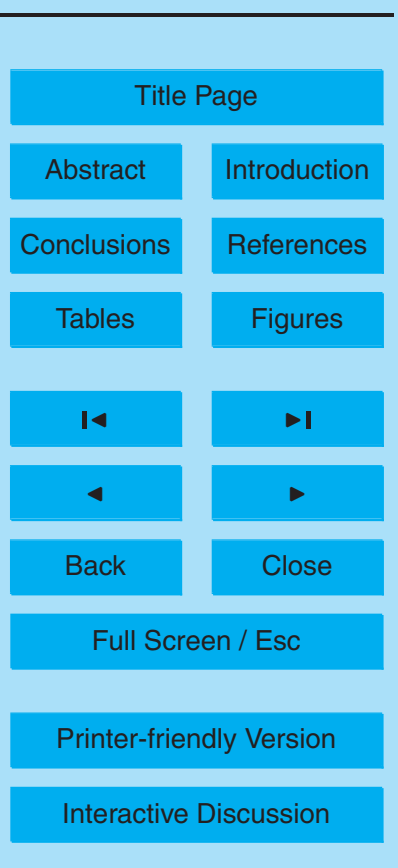

EGU 
well below saturation. In this study, the possibility of scattering by droplets and mirror absorption were both checked and eliminated as a source of the signal. This study attempted to measure the enhancement of water dimer absorption at 397-532 nm and the lack of water dimer absorption at $570 \mathrm{~nm}$.

\section{Materials and methods}

For these experiments water vapor was generated by bubbling zero grade air through Millipore purified water with a resistivity greater than 15 mega ohms or EMD brand OmniSolv water in a micro-impinger held at constant temperature. $\mathrm{D}_{2} \mathrm{O}$ was obtained from Acros with 99.8 atom\% D. The water was degassed by bubbling zero grade air through the impinger at temperatures above $70^{\circ} \mathrm{C}$ for $10 \mathrm{~min}$. Impurities were noted in the Millipore water from liquid phase spectra that were concentrated by the degassing procedure suggesting that they remained in the water. The impurities were absent in the OmniSolv water, and the cross section in the gas phase was not affected by the water source. When the water level was low in the bubbler, it was possible to obtain low read15 ings due to lower levels of saturation, and when bubbles were not avoided the readings became high due to droplets of water depositing downstream of the low temperature region of the bubbler. For this reason a dew point hygrometer was added inline downstream of the CRDS sample cell to measure the resulting water vapor concentration. A third complication was that initial readings were sometimes high particularly after 20 measurements of ambient $\mathrm{NO}_{2}$ and calibration gas possibly due to out-gassing of $\mathrm{NO}_{2}$ from the system that leveled out consistently within three measurements to the same levels as more water vapor was put through the system. A flow rate of $0.25 \mathrm{~L} \mathrm{~min}^{-1}$ was found to be optimal to avoid bubbles. Approximately 15 feet of Teflon tubing led from the bubbler to a $0.45 \mu \mathrm{m}$ filter at the inlet of the sample cell allowing for some time temperatures, an empty glass trap was added after the filter and heated in a water bath to the required temperatures along with heating tape to heat the sample cell.

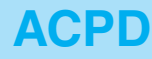

7, 11123-11140, 2007

\section{Water dimer light \\ J. Hargrove} absorption of visible

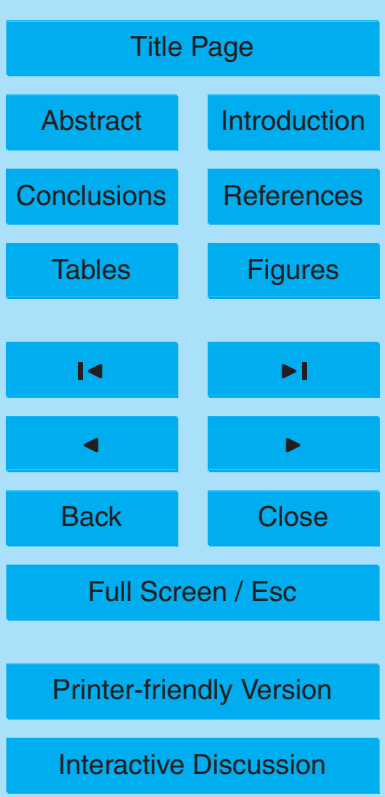

EGU 
In recent years, CRDS has been applied in many reported studies and the details of operation have been reported previously (Wang and Zhang, 2000; Hargrove, 2006; Wang et al., 2006). The thousands of reflections that occur in the optical cavity enhance CRDS sensitivity. The rate of decay of the light is measured rather than the 5 magnitude of attenuation to minimize the effect of light intensity variations. The dry air filled cavity rate of decay is subtracted from the sample rate of decay and divided by the speed of light to obtain the absorption coefficient. Near-UV laser radiation in the region of $405 \mathrm{~nm}\left(1-2 \mathrm{~mJ} /\right.$ pulse, line width $\left.0.2-0.3 \mathrm{~cm}^{-1}\right)$ was generated from frequency doubling the $810 \mathrm{~nm}$ output of an Nd:YAG $532 \mathrm{~nm}$-pumped dye laser (LDS 798 and 10 LDS 821 dyes). The cavity mirrors have reflectivity better than $99.995 \%$ at $405 \mathrm{~nm}(\mathrm{Re}-$ search Electro-Optics, diameter $=20 \mathrm{~mm}$, and radius of curvature $(\mathrm{ROC})=1 \mathrm{~m})$. The ring-down signal was collected on a 14-bit $200 \mathrm{MS} / \mathrm{s}$ oscilloscope card (Gage) and each ring-down event was curve fitted before averaging. To achieve this, a fast algorithm developed by Halmer and von Basum (2004) written in $\mathrm{C}++$ was used in combination with data collection software written in house starting from the Gage software development kit using National Instruments Labview v.7.1. Experiments using the buffer chambers involved providing two additional inlets and outlets for the chamber and matching the flow rates into and out of the three regions of the sample chamber to minimize mixing between the regions. For temperature controlled studies the entire chamber was wrapped with heating tape. The center glass tube and steel end chambers were controlled separately with two Variacs and kept within a few tenths of a degree from each other. Soft large O-ring seals at the mirrors limited the upper temperature obtainable to $35^{\circ} \mathrm{C}$, but since there was a significant drop in signal even at $35^{\circ} \mathrm{C}$ a high temperature cell was deemed unnecessary. Spectra were taken in three parts with measurements taken at the endpoints of the spectra to correct for baseline drift by subtracting values from the baseline and interpolating. Noise in the spectra was enhanced relative to other experiments because the scanning process takes considerable time. With this technique a tradeoff has to be made between better noise in a slow scan and less baseline drift in a fast scan.

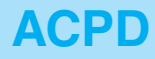

7, 11123-11140, 2007

\section{Water dimer \\ absorption of visible light \\ J. Hargrove}

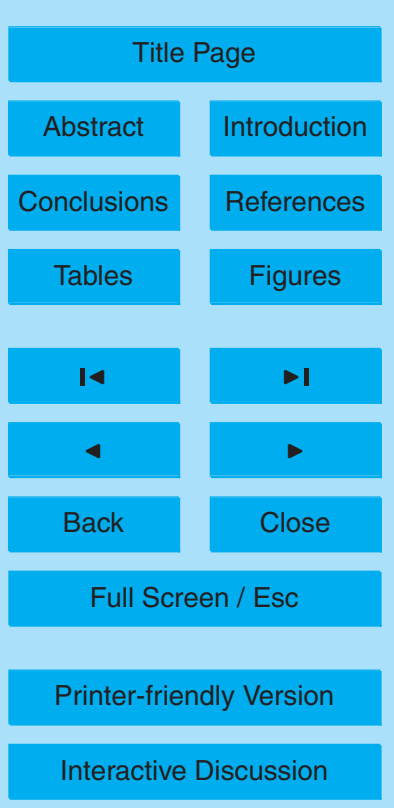




\section{Results and discussion}

Ambient measurements of $\mathrm{NO}_{2}$ at $405 \mathrm{~nm}$ found that there was interference from water vapor (Hargrove, 2006; Wang et al., 2006). The scans taken from $410 \mathrm{~nm}$ down to $397 \mathrm{~nm}\left(24400\right.$ to $25200 \mathrm{~cm}^{-1}$ ) show a broad absorption without significant structure.

5 Shorter scans showed some evidence of water monomer peaks below $400 \mathrm{~nm}$ but were not well resolved from the noise. Water monomer peaks have been detected previously in this region (Dupre, 2005; Gherman et al., 2005; Tolchenov, 2005; Naumenko et al., 2005), mostly below $400 \mathrm{~nm}$. Multiple scans were conducted and yielded a minimum at $400 \mathrm{~nm}\left(25000 \mathrm{~cm}^{-1}\right)$ and a peak at $409.5 \mathrm{~nm}\left(24420 \mathrm{~cm}^{-1}\right)$ that contained no evidence of $\mathrm{NO}_{2}$ features from any contamination. The limit of detection in this region was $2.6 \times 10^{-9} \mathrm{~cm}^{-1}$ for $10 \mathrm{~s}$ of averaging. Further averaging of 9 points each was used to obtain the Beer-Lambert plots, corrected baseline, and temperature dependence.

Three aspects of the water absorption were examined at $405 \mathrm{~nm}$ : the absorption spectrum to study the breadth of the absorption, the water monomer concentration dependence, and the temperature dependence to test the possibility of water dimer as a source of the signal. At $532 \mathrm{~nm}$ the concentration dependence was established but temperature dependence was not attempted because the temperature dependence would require measurements at multiple concentrations and curve fitting to remove the linear component, and would require better sensitivity. Wavelength dependence could not be studied at $532 \mathrm{~nm}$ because the measurements were not taken with a tunable laser. This would be an interesting topic for future study. The absorptions at 405 and $532 \mathrm{~nm}$ are not likely due to water monomer, as water monomer has sharp absorptions to the red and blue of $405 \mathrm{~nm}$ and $532 \mathrm{~nm}$ that do not overlap. The absorption at $405 \mathrm{~nm}$ could be attributed to either water dimer absorption or water vapor far wing continuum absorption due to water collisions with water molecules. Far wing continuum theories likely would predict a much weaker absorbance, with stronger absorptions to the red, though modeling of this effect is ongoing. Far wing continuum may cause the linear component at $532 \mathrm{~nm}$ but better sensitivity is needed before temperature dependent

\section{Water dimer \\ absorption of visible light \\ J. Hargrove}

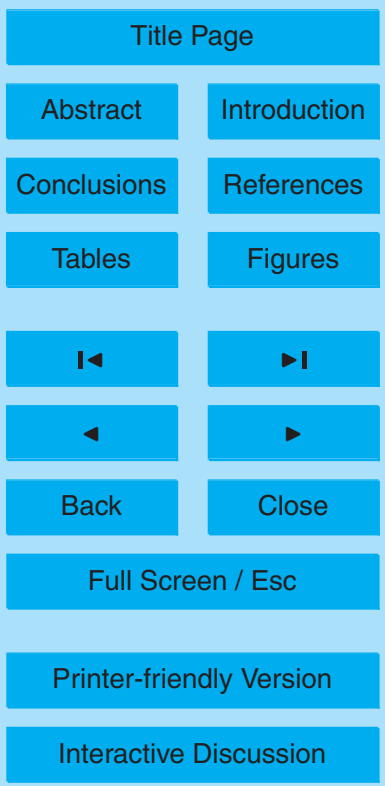


studies will be useful. The continuum at $570 \mathrm{~nm}$ is linear with respect to monomer (Fig. 2), has no temperature dependence, and is just between two water monomer peaks (Fig. 3). The source of this absorption is not clear, but could be due to collisions. So three regions were present where absorption was measurable the next step was to 5 measure the dependence on water monomer concentration.

The dependence of the absorption on water monomer concentration was the first indication that water dimer might be involved. At $405 \mathrm{~nm}$ there is a simple quadratic dependence suggesting that only water dimer contributes to the signal. At $532 \mathrm{~nm}$ there seems to be a mix of water dimer absorption and water monomer absorption resulting 10 in a curve that does not follow a simple quadratic dependence i.e. there is a linear component. At $570 \mathrm{~nm}$ the response is apparently linear despite some noise during data collection (Fig. 2). The limit of detection in these measurements was $2.6 \times 10^{-9} \mathrm{~cm}^{-1}$ and was signal averaged to obtain background noise less than $1 \times 10^{-9} \mathrm{~cm}^{-1}$. The extra noise in the $570 \mathrm{~nm}$ linearity data was due to uneven baseline drift during mea15 surements that day. Baseline drift was often a problem and motivated the development of a rigid sample cell with low thermal expansion for future studies. Despite these problems it was clear that no evidence of water dimer absorption was present at $570 \mathrm{~nm}$. The $0.3 \mathrm{~cm}^{-1}$ line widths of the water monomer peaks at $570 \mathrm{~nm}$ were used to verify that water monomer peaks at $400 \mathrm{~nm}$ would be difficult to observe relative to the noise.

Though it is agreed that water does dimerize in the gas phase, there has been controversy over whether water dimer contributes to continuum absorption, because bound states might not be thought to produce strong or broad spectra (R. Tipping, personal communication). However, water dimer vibrational transitions would be expected to show a greater density of states and the resulting spectra would be broadened by predissociation. The broad absorption at $409 \mathrm{~nm}$ showed a negative temperature dependence as would be expected for dimer absorption (Fig. 4). At $405.26 \mathrm{~nm}$, van't Hoff plots were constructed over a temperature interval of $21^{\circ} \mathrm{C}$ to $35^{\circ} \mathrm{C}$ and the equilibrium constant of dimerization and dimer cross section were reiteratively calculated resulting in equilibrium constant of $\mathrm{K}_{\mathrm{eq}}=0.056 \pm 0.02 \mathrm{~atm}^{-1}$, water dimer cross section of

\section{Water dimer absorption of visible light \\ J. Hargrove}

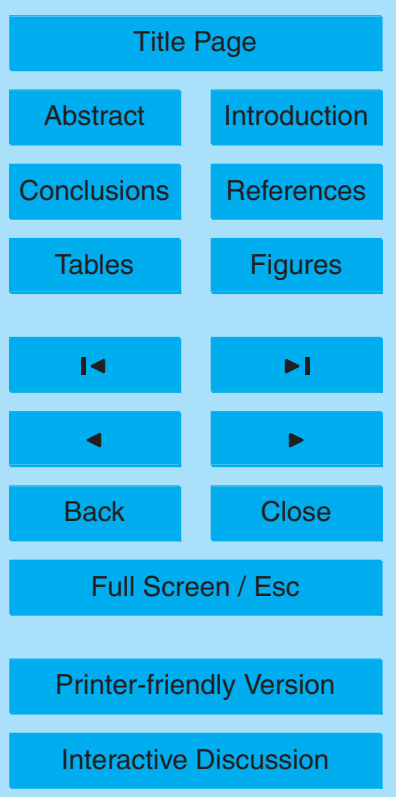

EGU 
$3.8 \times 10^{-22} \mathrm{~cm}^{2}$ molecule ${ }^{-1}$, enthalpy change of $-16.6 \pm 2 \mathrm{~kJ} \mathrm{~mol}^{-1}$, and entropy change of $-80 \pm 10 \mathrm{~J} \mathrm{~mol}^{-1} \mathrm{~K}^{-1}$.

The possibility of other water containing clusters was considered. A cluster with another species like $\mathrm{NO}_{2}$ would have to contain 2 water molecules to produce the 5 quadratic response and thermodynamics observed. It is likely that the bonding would be similar to water dimer but with one component at trace levels so that the concentration would be exceedingly small. It was calculated that the $\mathrm{NO}_{2} 2 \mathrm{H}_{2} \mathrm{O}$ trimer would be 1800 times less abundant than the individual pair and could be the only significant chromophore to get simple quadratic absorption. Thus, for this data to come from clusters of water with other species like $\mathrm{NO}_{2}$ would be exceedingly unlikely.

Two tests to evaluate the possibility of surface absorption on the ring-down cavity mirrors found no evidence of surface-absorbed water light absorption. The first test measured the water response in the presence of added buffer chambers at each end of the sample cell. The only loss of signal was equivalent to the loss of path-length by the addition of the buffer chambers. Also, heating the mirrors to $40^{\circ} \mathrm{C}$ had no effect on the signal. The cross section at $405 \mathrm{~nm}$ would correspond to $1 \mathrm{~mm}$ of liquid water on each mirror (Sogandares and Fry, 1997), so any mirror sorption should not be detectable unless there is an unusual thin film effect on the mirror reflectivity, which was ruled out by these tests.

20 As an additional check of the mechanism, measurements were taken with $\mathrm{D}_{2} \mathrm{O}$ in place of $\mathrm{H}_{2} \mathrm{O} . \mathrm{D}_{2} \mathrm{O}$ would be expected to absorb at longer wavelengths so that the measurements should be off-peak. The absorption due to $\mathrm{D}_{2} \mathrm{O}$ at $405 \mathrm{~nm}$ was actually measurable. It was linear with respect to concentration, and increased smoothly to the blue $\left(1.0 \times 10^{-25} \mathrm{~cm}^{2}\right.$ molecule ${ }^{-1}$ at $405 \mathrm{~nm}$ and $1.6 \times 10^{-25} \mathrm{~cm}^{2}$ molecule ${ }^{-1}$ at $\left.397 \mathrm{~nm}\right)$. 25 It is surprising that the cross section is as high as it is but it is still lower than for $\mathrm{H}_{2} \mathrm{O}$. $\mathrm{D}_{2} \mathrm{O}$ has a lower vapor pressure than $\mathrm{H}_{2} \mathrm{O}$ so any Mie scattering by water droplets or surface effect should be stronger with $\mathrm{D}_{2} \mathrm{O}$. The linear water monomer dependence suggests that there was no $\mathrm{D}_{2} \mathrm{O}$ dimer measurable at $405 \mathrm{~nm}$ as expected. This low $\mathrm{D}_{2} \mathrm{O}$ response helped rule out the possibility of droplet and surface absorption artifacts.

\section{Water dimer \\ absorption of visible light \\ J. Hargrove}

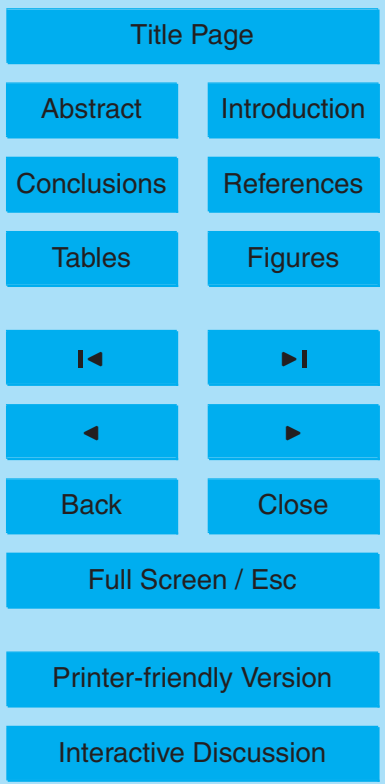


The thermodynamics of water dimer formation in the atmosphere has been the subject of several calculations (Schenter et al., 2002, 2003; Goldman, 2004, 2005; Leforestier et al., 2004, 2005). The most recent (Scribano, 2006; Goldman et al., 2006) suggest that in this temperature range $\Delta \mathrm{H}=-19.2 \mathrm{~kJ} \mathrm{~mole}^{-1}$ and $\Delta \mathrm{S}=90 \mathrm{~J} \mathrm{~mol}^{-1} \mathrm{~K}^{-1}$ pro5 ducing an equilibrium constant in agreement with ours $\left(0.051 \mathrm{~atm}^{-1}\right.$ vs. $\left.0.056 \mathrm{~atm}^{-1}\right)$. It has been difficult to confirm these calculations previously due to the lack of spectroscopic data on the dimer. The dissociation energy agrees with previous measurements by thermal conductivity (Curtiss, 1979; Frurip et al., 1979), an extrapolation of the analysis of the 3rd order term of the virial equation for steam to room temperature (Slanina 10 et al., 2006), and the recent spectroscopic measurements (Ptashnik et al., 2004). The cross section and equilibrium constant calculated in this paper are both perhaps surprisingly high. The equilibrium constant is in agreement with theory and the cross section may have been enhanced by the greater density of states above the dissociation limit (Schenter et al., 2002). From the nature of the measurements it is implied that 15 if either is actually smaller then the other is correspondingly larger, notwithstanding any measurement errors.

The simple quadratic absorption at $405 \mathrm{~nm}$ and the enthalpy and entropy calculated from the van't Hoff analysis are consistent with water dimer as the source but do not exclude the possibility of far wing continuum absorption. The greater density of states present in the dimer configuration could enhance the vibrational overtone bands of water dimer. Periodic shifting of charge density within the dimer may also enhance absorption. There is a shift in the water dimer wavefunctions in the overtones due to an unusual anharmonicity effect starting near the $v=6$ level that may cause lobes of the 8th overtone to overlap significantly with the ground state wavefunction (Huang et al.,

2006; Schofield et al., 2007). This could partly explain the relatively large magnitude of the $\sim \Delta \mathrm{V}=8$ absorption at $405 \mathrm{~nm}$ in comparison to the $\sim \Delta \mathrm{V}=6$ absorption at $532 \mathrm{~nm}$. The $v=7$ overtone should be measurable at about $440 \mathrm{~nm}$ and comparable absorption has been observed with a diode based cavity attenuated phase shift (CAPS) $\mathrm{NO}_{2}$ detector operating from $430-450 \mathrm{~nm}$ (A. Freedman, personal communication).

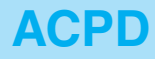

7, 11123-11140, 2007

\section{Water dimer \\ absorption of visible light \\ J. Hargrove}

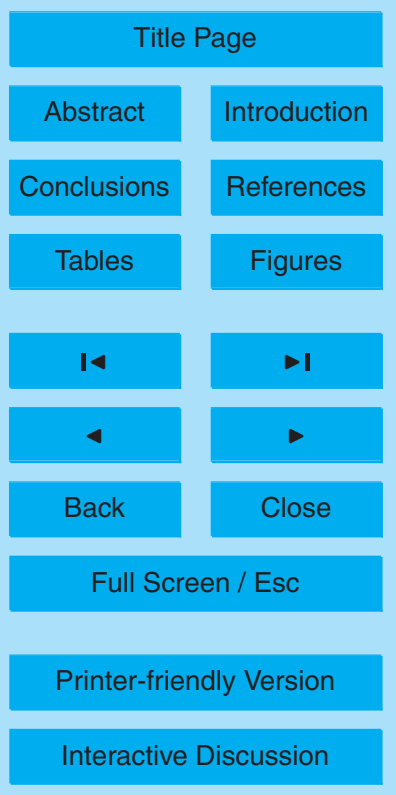

EGU 
Remarkably, the dimer cross section at $405 \mathrm{~nm}$ is $10^{5}$ times stronger than that liquid water (Sogandares and Fry, 1997). This appears to be due to a shift in the frequency and enhancement in the magnitude of the overtone transitions involved. It is unlikely that this feature is due to Rayleigh scattering of water vapor, because 5 the Rayleigh scattering cross-section for water vapor is less than that of nitrogen or oxygen (Tomasi et al., 2005). Mie scattering by droplets is also unlikely. Droplets would have to pass through or be generated by the $0.45 \mu \mathrm{m}$ filter used immediately upstream in this study. A filter of this type is commonly attributed to remove particles an order of magnitude smaller than the pore size, and if it were possible for droplets to 10 be generated from the surface of the filter, the droplets would likely be formed for some time after switching to the baseline. Tests without the filter also showed the same cross section. Ambient tests with $\mathrm{NO}_{2}$ removed by a denuder coated with sodium hydroxide and guiacol showed absorption consistent with water dimer at the local humidity level.

One consequence of this absorption is that ambient measurements of trace gasses by optical spectroscopy may have to account for water vapor interference. More significant, however, is the consequence for radiative forcing calculations. A significant portion of the $15-30 \mathrm{~W} \mathrm{~m}^{-2}$ discrepancy between the calculated and actual amount of radiation absorbed by the atmosphere could be due to water dimer absorption. The large magnitude of the signal at $405 \mathrm{~nm}$, and the signal at $532 \mathrm{~nm} \sim 5$ times that of Tso 20 et al. (1998) $\left(2.7 \times 10^{-22} \mathrm{~cm}^{2}\right.$ cf. $\left.6 \times 10^{-23} \mathrm{~cm}^{2}\right)$, even with the greater density of states above the dissociation limit (Schenter et al., 2002) is hard to justify. The additional absorption at $405 \mathrm{~nm}$ is beyond $20000 \mathrm{~cm}^{-1}$ as well, was not considered in their estimate, and will contribute a similar amount of additional absorption. Calculations of the water dimer cross section from a 1-dimensional potential (Schofield et al., 2007) and 25 extended to $\Delta v=8$ have resulted in very small oscillator strengths $\left(10^{-13}\right)$, but more recent calculations based on the full potential energy surface (Huang et al., 2006) have been closer $\left(10^{-10}\right)$. However, these calculations still do not agree due to the broad nature of the absorption that could add another three orders of magnitude to the measured oscillator strength. These cross sections may seem unreasonable, but it has

\section{Water dimer absorption of visible light \\ J. Hargrove}

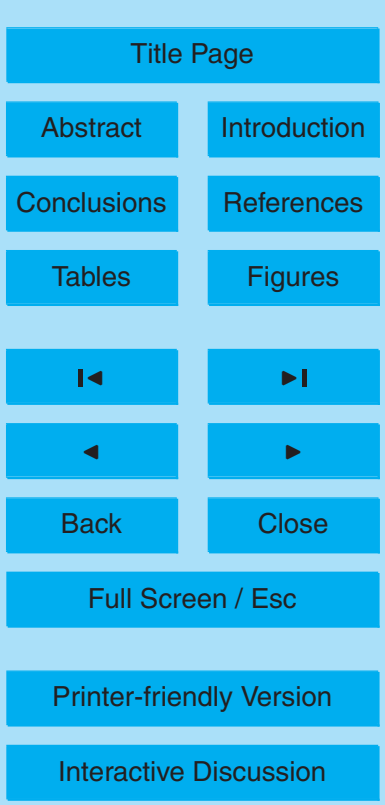


been shown that good cross sections for $\mathrm{NO}_{2}$ can be obtained with this instrumentation in the same region of the spectrum. It is anticipated that other groups will not have difficulty reproducing these measurements.

The consequence of these absorptions in the atmosphere will be an increase in cal5 culated positive water vapor feedback, though another additional effect may be cooler surface temperatures and warmer air temperatures. If global warming continues as is anticipated, the increased air temperatures will lead to greater levels of water vapor in the atmosphere. With greater levels of water vapor the increase in water dimer will be nearly quadratic, and increase the direct absorption of sunlight to a greater extent 10 than would be predicted by empirical models based on water monomer absorption and line broadening. This would be offset partially by the shift in equilibrium at higher temperatures to favor water monomer, but the net result would likely be to enhance the warming effect. Conversely, if greenhouse gasses subside, the result would be to enhance the cooling effect. The calculations required to model this system have not yet been undertaken and will require accurate cross sections at all relevant wavelengths and an accurate model of the thermodynamics. It is hoped that in the near future these factors will be determined with higher precision and applied to predict future global temperatures with greater accuracy. It has been recently reported that climate change is happening faster than current models predict (Rahmstorf et al., 2007) so it is possible the effect of this water absorption needs to be taken into account.

Acknowledgements. Thanks to M. Okumura, K. Takematsu, V. Vaida, and F.-M. Tao for useful discussion, and to D. Fitz and ce-cert for the loan of their hygrometer. Thanks to D. Shofield et al. and X. Huang et al. for extending their calculations to $v=8$. Thanks to J. Zhang for his patience and generous help in what has been a challenging discovery. Thanks also to 25 D. Medina and P. Stavros for assistance with experiments. This work was supported by the National Science Foundation.

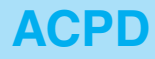

7, 11123-11140, 2007

\section{Water dimer light \\ J. Hargrove}

absorption of visible

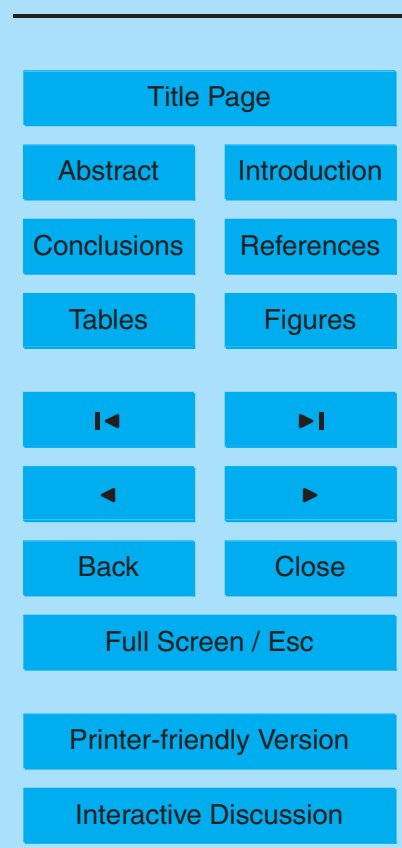




\section{References}

Arking, A.: Absorption of solar energy in the atmosphere: Discrepancy between model and observations, Science, 273(5276), 779-782, 1996.

Arking, A.: The influence of clouds and water vapor on atmospheric absorption, Geophys. Res.

$5 \quad$ Lett., 26(17), 2729-2732, 1999.

Camy-Peyret, C. and Vigasin, A. A. (Eds.): Weakly interacting molecular pairs: unconventional absorbers of radiation in the atmosphere, Dordrecht; Boston, Kluwer Academic Publishers, 2003.

Carlon, H. R.: Do Clusters Contribute to the Infrared-Absorption Spectrum of Water-Vapor, Infrared Physics, 19(5), 549-557, 1979.

Cormier, J. G., Hodges, J. T., and Drummond, J. R.: Infrared water vapor continuum absorption at atmospheric temperatures, J. Chem. Phys., 122(11), 114309, doi:10.1063/1.1862623, 2005.

Curtiss, L. A., Frurip, D. J., and Blander, M.: Studies of Molecular Association in H2o and D2o Vapors by Measurement of Thermal-Conductivity, J. Chem. Phys., 71(6), 2703-2711, 1979.

Dupre, P., Gherman, T., Zobob, N. F., et al.: Continuous-wave cavity ringdown spectroscopy of the $8 \mathrm{nu}$ polyad of water in the $25195-25340 \mathrm{~cm}^{(-1)}$ range, J. Chem. Phys., 123(15), 154 307, doi:10.1063/1.2055247, 2005.

English, S. J., Guillou, C., Prigent, C., and Jones, D. C.: Aircraft Measurements of WaterVapor Continuum Absorption at Millimeter Wavelengths, Q. J. Roy. Meteor. Soc., 120(517), 603-625, 1994.

Fomin, B. A. and Udalova, T. A.: Spectroscopic databases and models of continuum absorption for computation of atmospheric radiation: A ten-year retrospective and the current state, Izvestiya Atmospheric and Oceanic Physics, 39(4), 466-475, 2003.

Goldman, N., Leforestier, C., and Saykally, R. J.: Water dimers in the atmosphere II: Results from the VRT(ASP-W)III potential surface, J. Phys. Chem. A, 108(5), 787-794, 2004.

Goldman, N., Leforestier, C., and Saykally, R. J.: A 'first principles' potential energy surface for liquid water from VRT spectroscopy of water clusters, Philosophical Transactions of the Royal Society of London Series a-Mathematical Physical and Engineering Sciences, 363(1827), 493-508, 2005.

Halmer, D., von Basum, G., Hering, P., and Murtz, M.: Fast exponential fitting algorithm for real-time instrumental use, Rev. Sci. Instr., 75(6), 2187-2191, 2004.

\section{Water dimer \\ absorption of visible \\ light}

J. Hargrove

Title Page

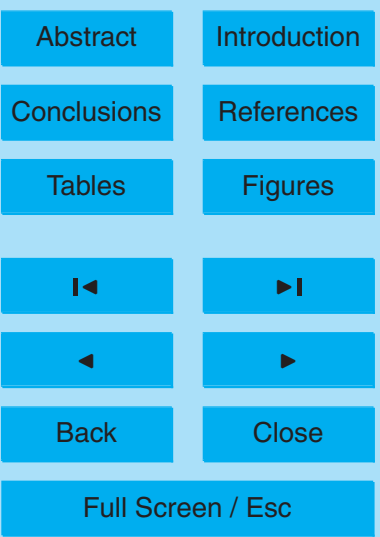

Printer-friendly Version

Interactive Discussion 
Hargrove, J., Wang, L., Muyskens, K., et al.: Cavity Ring-Down Spectroscopy of Ambient $\mathrm{NO}_{2}$ with Quantification and Elimination of Interferences, Environ. Sci. Technol., 40(24), 78687873, 2006.

Held, I. M. and Soden, B. J.: Water vapor feedback and global warming, Ann. Rev. Energy Environ., 25, 441-475, 2000.

Hewison, T. J.: Aircraft validation of clear air absorption models at millimeter wavelengths (89$183 \mathrm{GHz}$ ), J. Geophys. Res.-Atmos., 111(D14), D14303, doi:10.1029/2005JD006719, 2006.

Hill, C. and Jones, R. L.: Absorption of solar radiation by water vapor in clear and cloudy skies: Implications for anomalous absorption, J. Geophys. Res.-Atmos., 105(D7), 9421$10 \quad 9428,2000$.

Howard, D. L. and Kjaergaard, H. G.: Influence of intramolecular hydrogen bond strength on OH-stretching overtones, J. Phys. Chem. A, 110(34), 10245-10250, 2006.

Huang, X. C., Braams, B. J., and Bowman, J. M.: Ab initio potential energy and dipole moment surfaces of $(\mathrm{H} 2 \mathrm{O})(2)$, J. Phys. Chem. A, 110(2), 445-451, 2006.

Kassi, S., Macko, P., Naumenko, O., and Campargue, A.: The absorption spectrum of water near $750 \mathrm{~nm}$ by CW-CRDS: contribution to the search of water dimer absorption, Phys. Chem. Chem. Phys., 7(12), 2460-2467, 2005.

Pfeilsticker, K.: How broad are water dimer bands? Response, Science, 304(5672), 823-824, 2004.

20 Pfeilsticker, K., Lotter, A., Peters, C., and Bosch, H.: Atmospheric detection of water dimers via near-infrared absorption, Science, 300(5628), 2078-2080, 2003.

Philipona, R., Durr, B., Ohmura, A., and Ruckstuhl, C.: Anthropogenic greenhouse forcing and strong water vapor feedback increase temperature in Europe, Geophys. Res. Lett., 32(19), L19809, doi:10.1029/2005GL023624, 2005.

Ptashnik, I. V., Smith, K. M., Shine, K. P., and Newnham, D. A.: Laboratory measurements of water vapour continuum absorption in spectral region $5000-5600 \mathrm{~cm}(-1)$ : Evidence for water dimers, Q. J. Roy. Meteor. Soc., 130(602), 2391-2408, 2004.

Rahmstorf, S., Cazenave, A., Church, J. A., et al.: Recent climate observations compared to projections, Science, 316(5825), 709-709, 2007.

30 Schenter, G. K., Kathmann, S. M., and Garrett, B. C.: Equilibrium constant for water dimerization: Analysis of the partition function for a weakly bound system, J. Phys. Chem. A, 106(8), 1557-1566, 2002.

Schofield, D. P., Lane, J. R., and Kjaergaard, H. G.: Hydrogen Bonded OH-Stretching Vibration

\section{Water dimer \\ absorption of visible light}

J. Hargrove

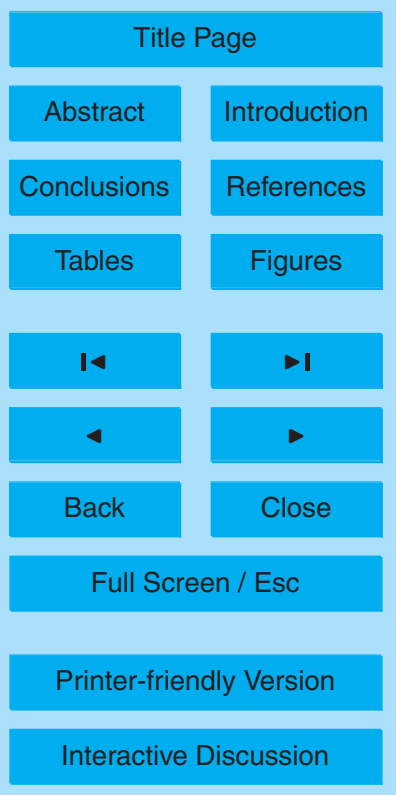


in the Water Dimer, J. Phys. Chem. A, 111(4), 567-572, 2007.

Scribano, Y., Goldman, N., Saykally, R. J., and Leforestier, C.: Water dimers in the atmosphere III: Equilibrium constant from a flexible potential, J. Phys. Chem. A, 110(16), 5411-5419, 2006.

5 Sierk, B., Solomon, S., Daniel, J. S., et al.: Field measurements of water vapor continuum absorption in the visible and near-infrared, J. Geophys. Res.-Atmos., 109(D8), 109, D08307, doi:10.1029/2003JD003586, 2004.

Slanina, Z., Uhlik, H., Lee, S. L., and Nagase, S.: Computational modelling for the clustering degree in the saturated steam and the water-containing complexes in the atmosphere, $J$.

10 Quant. Spectr. Radiat. Trans., 97(3), 415-423, 2006.

Sogandares, F. M. and Fry, E. S.: Absorption spectrum $(340-640 \mathrm{~nm})$ of pure water. 1. Photothermal measurements, Appl. Optics, 36(33), 8699-8709, 1997.

Tolchenov, R. N., Naumenko, O., Zobov, N. F., et al.: Water vapour line assignments in the 9250-26 $000 \mathrm{~cm}(-1)$ frequency range, J. Molecular Spectr., 233(1), 68-76, 2005.

Tomasi, C., Vitale, V., Petkov, B., Lupi, A., and Cacciari, A.: Improved algorithm for calculations of Rayleigh-scattering optical depth in standard atmospheres, Appl. Optics, 44(16), 33203341, 2005.

Tso, H. C. W., Geldart, D. J. W., and Chýlek, P.: Anharmonicity and cross section for absorption of radiation by water dimer, J. Chem. Phys., 108(13), 5319-5329, 1998.

Vaida, V., Daniel, J. S., Kjaergaard, H. G., et al.: Atmospheric absorption of near infrared and visible solar radiation by the hydrogen bonded water dimer, Q. J. Roy. Meteor. Soc., 127(575), 1627-1643, 2001.

Wang, L. M. and Zhang, J. S.: Detection of nitrous acid by cavity ring down spectroscopy, Environ. Sci. Technol., 34(19), 4221-4227, 2000.

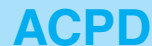

7, 11123-11140, 2007

\section{Water dimer \\ absorption of visible \\ light}

J. Hargrove

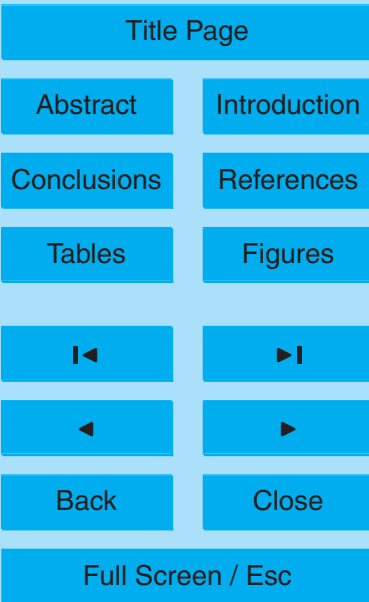

Printer-friendly Version

Interactive Discussion 


\section{ACPD}

7, 11123-11140, 2007

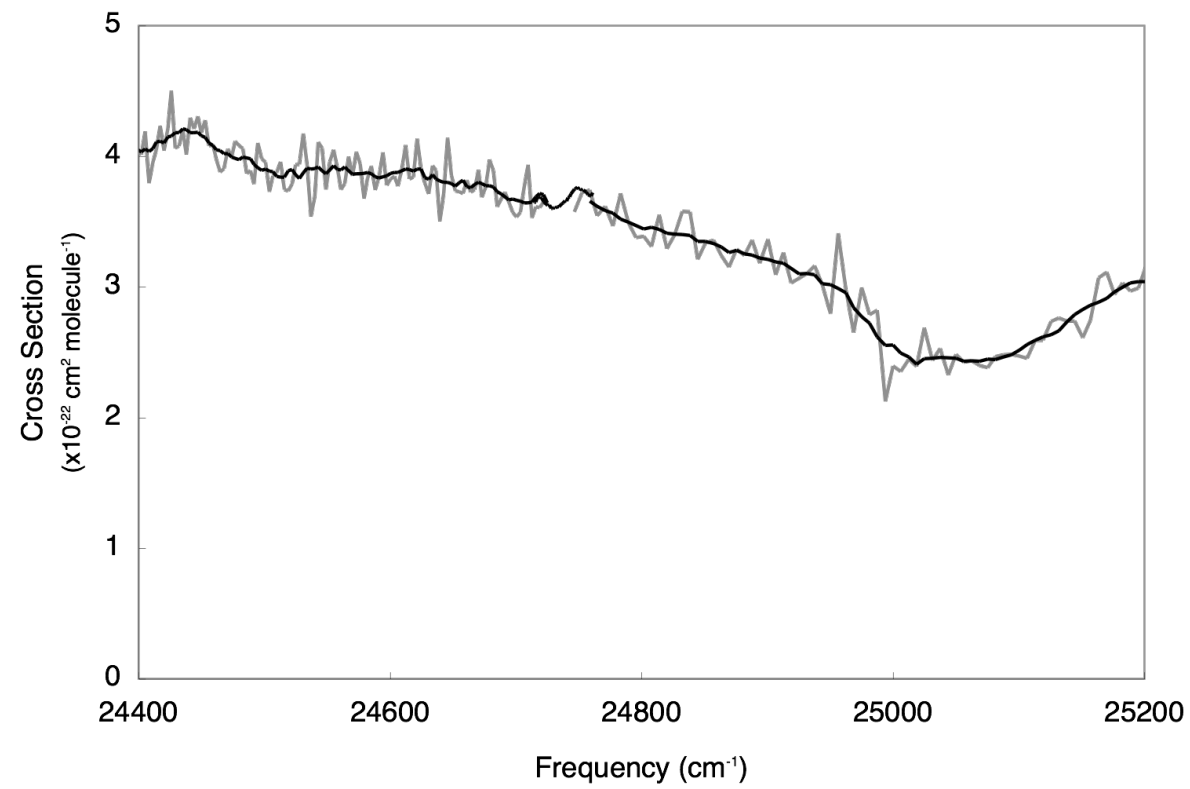

Water dimer absorption of visible light

J. Hargrove

Title Page

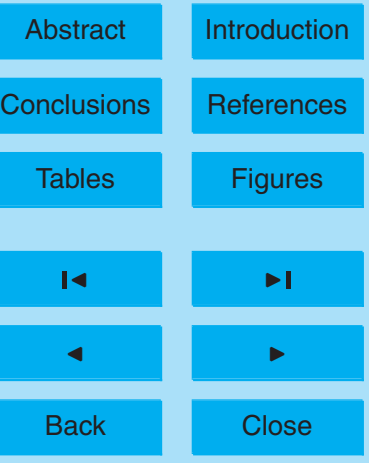

Full Screen / Esc

Fig. 1. The spectrum of water dimer near $405 \mathrm{~nm}$, showing the junction of a pair of broad absorption features with a minimum near $25000 \mathrm{~cm}^{-1}$, and unexpectedly high cross sections. The solid line shows 9 point smoothing of the raw data in grey.

Printer-friendly Version

Interactive Discussion 

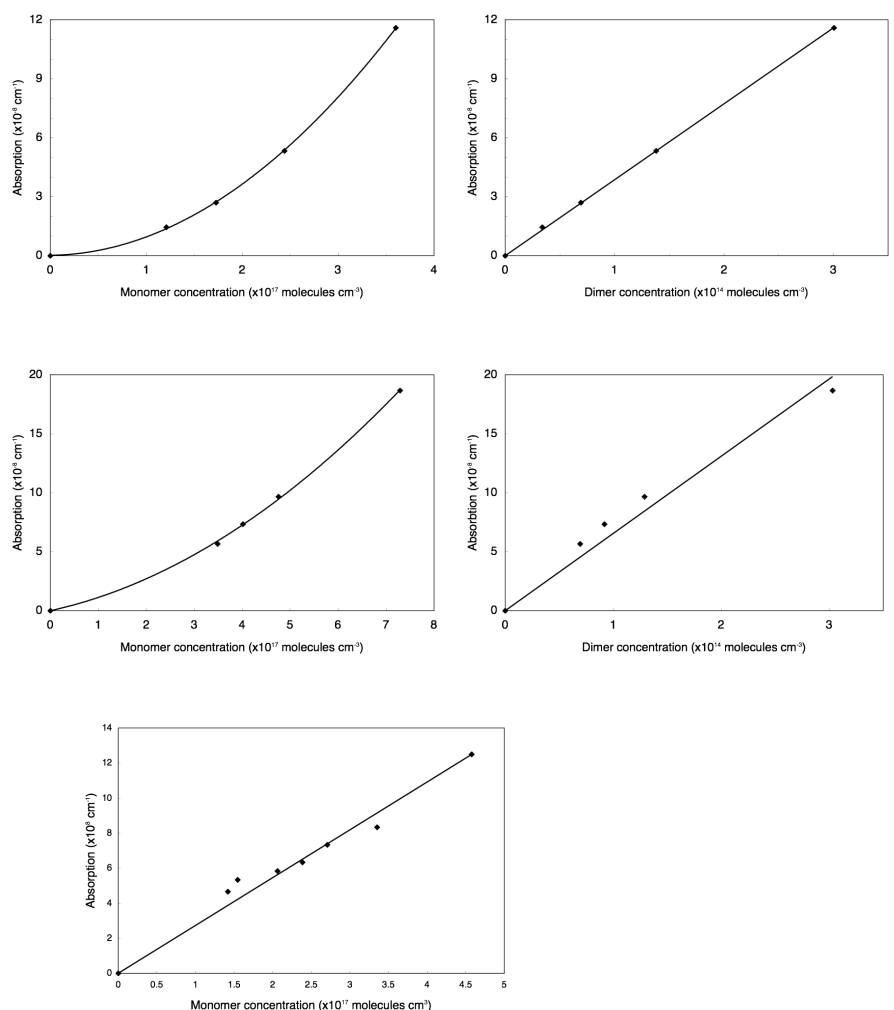

Fig. 2. Beer-Lambert law plots assuming absorption due to (a) water monomer and (b) water dimer at $405 \mathrm{~nm}$ (c and d) $532 \mathrm{~nm}$ and (e) monomer at $570 \mathrm{~nm}$. There is a simple quadratic dependence at $405 \mathrm{~nm}$. The water dimer graph calculated using the equilibrium constant we obtained follows the Beer-Lambert law with a dimer cross section of $3.8 \times 10^{-22} \mathrm{~cm}^{2}$ molecule ${ }^{-1}$. At $532 \mathrm{~nm}$, a linear term is present in the monomer plot yielding a monomer cross section of $1.5 \times 10^{-25} \mathrm{~cm}^{2}$ molecule ${ }^{-1}$ and dimer cross section of $2.7 \times 10^{-22} \mathrm{~cm}^{2}$ molecule ${ }^{-1}$. At $570 \mathrm{~nm}$ only a linear $1.0 \times 10^{-25} \mathrm{~cm}^{2}$ molecule ${ }^{-1}$ continuum is present.

\section{ACPD}

7, 11123-11140, 2007

\section{Water dimer \\ absorption of visible light}

J. Hargrove

Title Page

Abstract

Introduction

Conclusions

References

Tables

Figures

14

1

4

Back

Close

Full Screen / Esc

Printer-friendly Version

Interactive Discussion 


\section{ACPD}

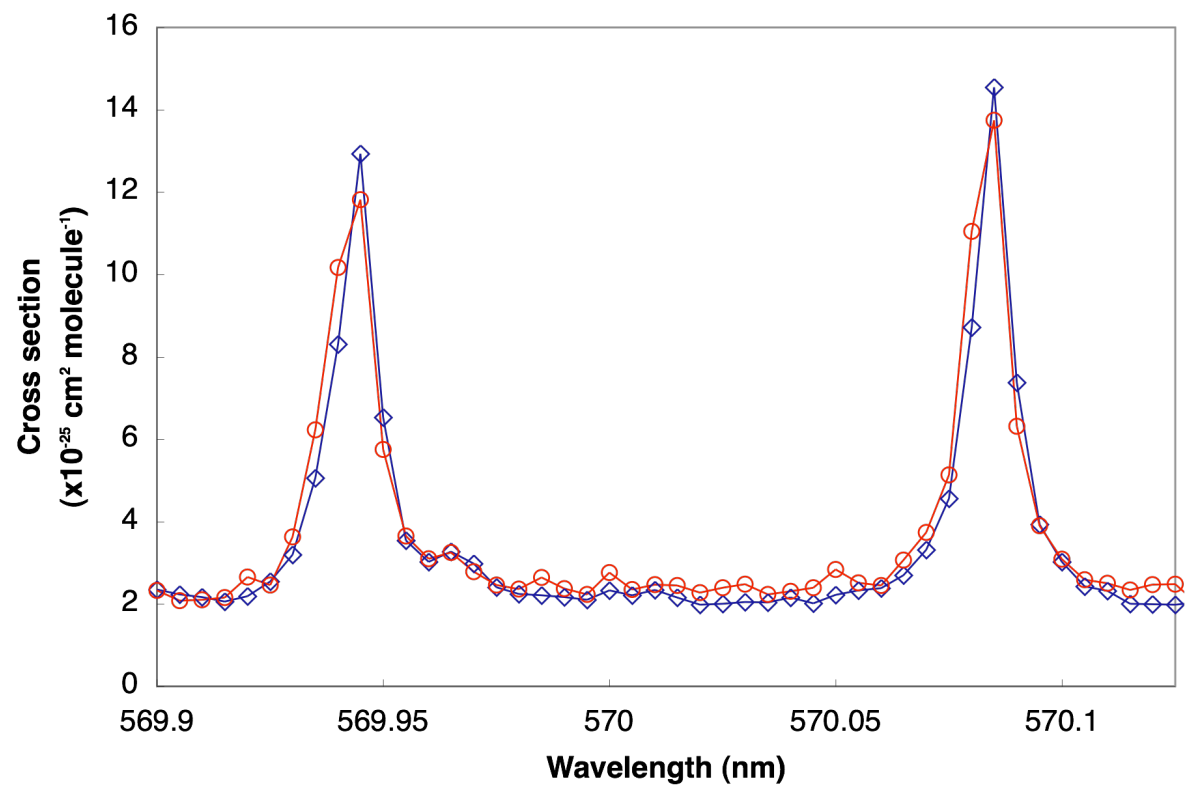

$\diamond 21$ oC $\bigcirc-30$ oC

Fig. 3. Absorption at $570 \mathrm{~nm}$ showing a broad continuum shift in the baseline with no temperature dependence or quadratic response in contrast to that at $410 \mathrm{~nm}$. The peaks present show a predictable broadening and shift to the blue as would be expected at higher temperatures.

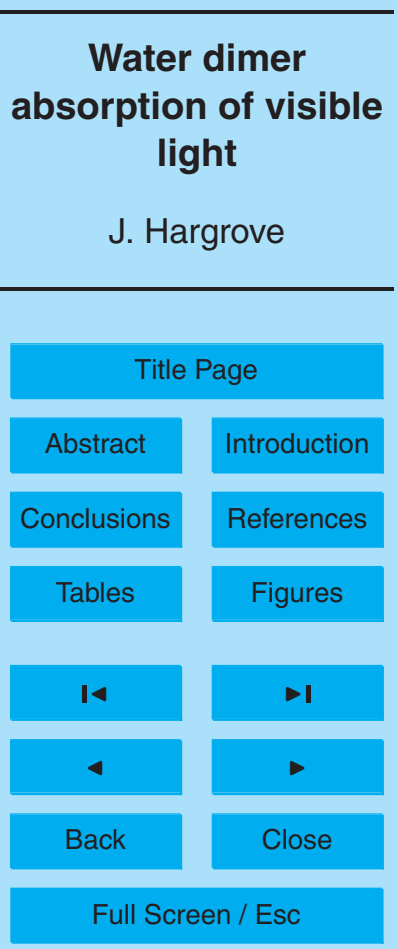

Printer-friendly Version

Interactive Discussion 


\section{ACPD}

7, 11123-11140, 2007

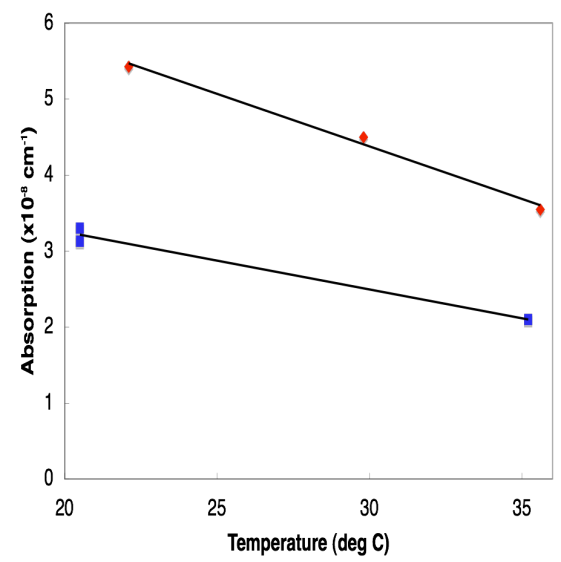

Fig. 4. Van't Hoff plot: Two experiments were performed with constant water vapor concentrations at a dew-point of $10^{\circ} \mathrm{C}$ (blue) and then $15^{\circ} \mathrm{C}$ (red). The enthalpy matches previous experiments and the equilibrium constant is close to the theoretical value of Scribano et al. but lower than the enthalpy and entropy (dotted line).

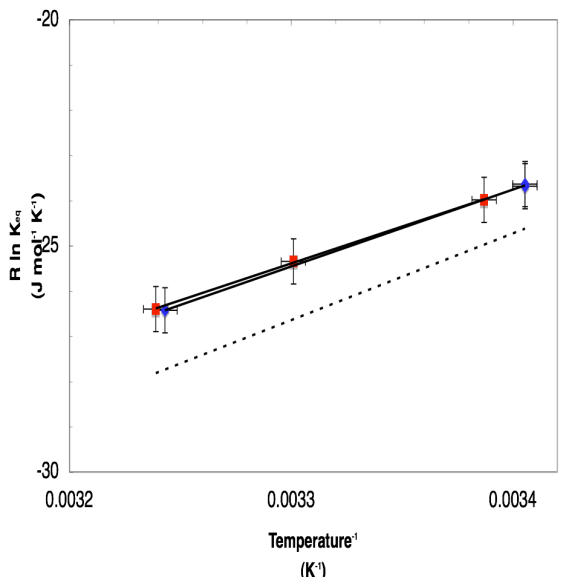

$\left(\mathbf{K}^{\prime}\right)$

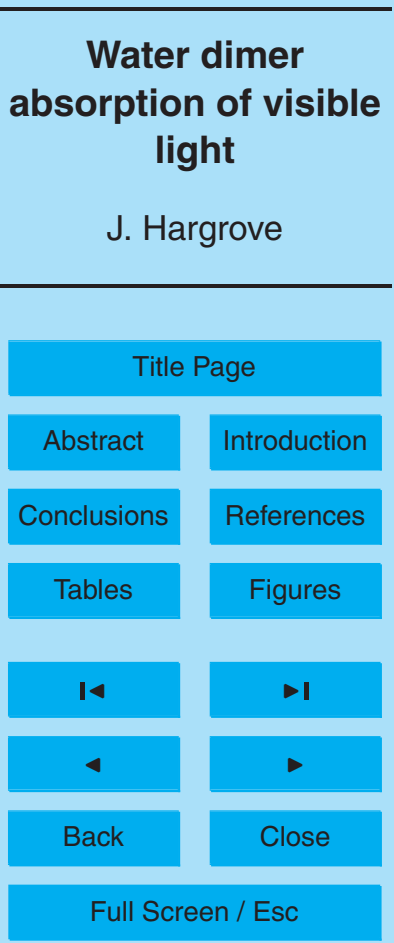

Printer-friendly Version

Interactive Discussion 